\title{
Técnica dietética e aceitação das preparações arroz e feijão em restaurantes na cidade do Rio de Janeiro- RJ, Brasil
}

\section{Dietary technical and acceptance of riceand beenpreparations in food services in Rio de Janeiro city}

Ana Victoria Regazone

Nathalia Nunes'

Joice Fialhol

Fabiana Bom Kraemer ${ }^{2}$

Odaleia Barbosa de Aguiar²

' Acadêmica bolsista de Nutrição, Instituto de Nutrição - Universidade do Estado do Rio de Janeiro. Rio de Janeiro, RJ, Brasil.

${ }^{2}$ Docentes do Departamento de Nutrição Aplicada, Instituto de Nutrição - Universidade do Estado do Rio de Janeiro. Rio de Janeiro, RJ, Brasil.

Correspondência / Correspondence Ana Victoria Regazone

E-mail: anavicre@gmail.com

\section{Resumo}

Introdução: O consumo de arroz e feijão nos últimos anos tem apresentado queda, entre os brasileiros, de $40,5 \%$ e $26,4 \%$, respectivamente. Acreditamos que através da qualidade sensorial na preparação destes alimentos, é possível vislumbrar uma melhor apreciação desses pratos. Objetivo: Identificar as técnicas dietéticas empregadas nas preparações arroz e feijão e analisar os atributos sensoriais. Materiais e métodos: Estudo do tipo descritivo, quantitativo realizado no ano de 2011, em quatro restaurantes de cardápios populares, localizados no município do Rio de Janeiro, compreendendo a construção de fichas técnicas de preparação e teste de aceitação sensorial das preparações aplicado aos funcionários dos restaurantes. Resultados e discussão: Identificaram-se técnicas dietéticas distintas nos restaurantes em estudo quanto à prática de lavagem do arroz, à temperatura da água utilizada para sua cocção, ao uso do remolho e temperos do feijão, bem como a técnica de espessamento da preparação. No teste de aceitação sensorial, a maioria dos funcionários relatou "gostar ligeiramente" das preparações, no entanto, 34,1\% (arroz) e 36,7\% (feijão) referiram não apreciar ou comer a preparação. Conclusão: torna-se necessário rever as técnicas de preparo do arroz e feijão, visando ao aumento no consumo de ambas nos restaurantes voltados para a coletividade.

Palavras-chave: Arroz. Feijão. Análise sensorial. Serviços de alimentação. Alimentação coletiva. 


\section{Abstract}

Introduction: The intake of rice and beans during the last years have indicated a decrease of $40,5 \%$ and $26,4 \%$ among Brazilians. We believe with a better sensory quality on cooking of these foods allows better appreciation of them. Objective: To identify the method of preparing rice and beans and to analyze the sensory attributes. Materials and methods: Descriptive and quantitative study, conducted in 2011, in four restaurants with popular menus in Rio de Janeiro city, including the formulation of technical data sheets of preparation and sensory acceptance tests of the preparations methods used by the restaurant employees. Results and discussion: Different dietary techniques were clearly identified in the restaurants investigated regarding the washing rice, the temperature of the water used for cooking, the use of spices in the beans and the practice of letting it soak, as well as the bean thickening preparation. Regarding the sensory acceptance tests, most of the employees reported slightly like the preparations, however, $34.1 \%$ (rice) and $36.7 \%$ (beans) reported not approving or eating them. Conclusion: It is necessary to review the methods for preparations of rice and beans with the objective of raising their consumption in restaurants.

Key words: Oryza sativa. Fabaceae. Sensory analysis. Food service. Collective feeding.

\section{Introdução}

Os hábitos alimentares da população de diferentes classes socioeconômicas, tanto urbana como rural, vêm sofrendo modificações que podem ser atribuídas a mudanças sociais e econômicas nas sociedades desenvolvidas ${ }^{1,2}$

A explicação para tal mudança pode ser dada, dentre outros aspectos, pelos determinantes sociais e econômicos, que são, respectivamente, o aumento do número de indivíduos que residem sozinhos, o modo de vida urbano, alimentação fora de casa, a entrada da mulher no mercado de trabalho, o tempo de almoço preestabelecido pelas empresas, as estratégias publicitárias, além da grande produção de alimentos industrializados prontos ou semiprontos para consumo, que durante o processamento industrial são adicionados de açúcar, sal, gorduras não saudáveis, conservantes, dentre outros, os

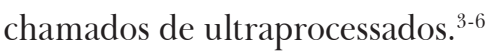

Esses acontecimentos soam como uma válvula de escape para aqueles que se dizem isentos de tempo hábil para produzir suas próprias refeições, e buscam assim 
a praticidade e rapidez do consumo das refeições feitas fora de casa.

Observa-se um declínio do consumo das preparações arroz e feijão nos últimos anos entre os brasileiros, de 40,5\% e 26,4\%, respectivamente, assim como de outros alimentos in natura ou minimamente processados pela indústria. Em contrapartida, aumentou o consumo de alimentos ultraprocessados. $\left.{ }^{4,7}\right)$. Esses dados são preocupantes, pois a persistência no consumo de alimentos ricos em açúcar e com elevado teor de gorduras aponta tendências desfavoráveis no padrão alimentar, sobretudo para o desenvolvimento de doenças crônicas não-transmissíveis.

Apesar do declínio no consumo de arroz e feijão, estes ainda se mantêm significativos, principalmente entre as classes menos favorecidas. A classe detentora de maior renda apresenta um consumo menor desses alimentos, devido à maior disponibilidade financeira e, consequentemente, maior aquisição de diferentes produtos. ${ }^{4}$

Nos restaurantes de alimentação coletiva, acreditamos que a diminuição do consumo de alimentos básicos e tradicionais da dieta dos brasileiros, como por exemplo, o arroz e o feijão, pode estar também relacionada à qualidade sensorial das refeições servidas. Segundo estudo feito por Mangabeira \& Botelho, ${ }^{8}$ os restaurantes que produzem refeições em larga escala devem se preocupar mais em compreender as expectativas de sua clientela, a fim de tornar a refeição fora de casa mais prazerosa, obtendo maior êxito em seu atendimento. $\mathrm{O}$ mesmo estudo indica que os restaurantes de alimentação coletiva devem tornar o modo de preparo do arroz e do feijão mais caseiro, resgatando o sabor tradicional dessa mistura brasileira, aumentando o desejo por esses alimentos.

O objetivo deste estudo foi identificar as técnicas dietéticas empregadas nas preparações arroz e feijão, bem como analisar a aceitação dessas nos restaurantes para coletividades do município do Rio de Janeiro-RJ, Brasil.

\section{Materiais e métodos}

Estudo do tipo descritivo e quantitativo realizado entre os meses de maio e julho do ano de 2011, em quatro restaurantes de cardápios populares, localizados no município do Rio de Janeiro, onde são desenvolvidas atividades de projetos de extensão e pesquisa das autoras. A estrutura do cardápio é composta diariamente por duas entradas (sopa e salada), prato principal e uma opção ao prato principal, compostos por preparações de base proteicas, guarnição, arroz e feijão, sobremesa com oferta de fruta ou doce e refresco. O sistema de distribuição do serviço é cafeteria com porcionamento das preparações pelas copeiras. Três restaurantes fornecem em média 3.000 refeições/dia na unidade de alimentação e nutrição (UAN I, UAN II e UAN III), e a UAN IV, 4.500.

O estudo teve as seguintes etapas: primeiro, elaborou-se a ficha técnica de preparação, para avaliar o modo de preparo do arroz e do feijão, 
que continha informações sobre: localização do restaurante, número de refeições ofertado pela unidade, data da coleta, nome do investigador, nome do responsável pela preparação, ingredientes e quantidades usados no preparo e suas respectivas marcas, embalagem e quantas unidades foram utilizadas na preparação e a técnica de preparo empregada. A ficha ainda apresentava peso bruto e líquido, fator de cocção e custo unitário de cada ingrediente utilizado, o tipo de rendimento, informação nutricional e análise sensorial.

Em seguida, elaborou-se um questionário para avaliar o hábito de consumo, a frequência e a aceitação sensorial dessas preparações, por 73 trabalhadores das unidades estudadas. Os provadores foram recrutados em função da inserção nos projetos de extensão e pesquisa mencionados, além do interesse em participarem do teste. Foram excluídos os cozinheiros, por serem os responsáveis pela execução das preparações.-

A análise sensorial das preparações arroz e feijão foi realizada por meio de teste de aceitação, no próprio restaurante, utilizando-se a escala hedônica estruturada de cinco pontos (desgostei muito, desgostei ligeiramente, indiferente, gostei ligeiramente e gostei muito). ${ }^{9}$ Os atributos avaliados pela escala hedônica foram cor, aparência, aroma, sabor e consistência. Ao formulário da análise sensorial foi acrescentado um espaço para as considerações gerais, para que os provadores pudessem expressar suas opiniões sobre as preparações.
Os dados obtidos no teste de aceitação foram submetidos à análise de distribuição de frequência.

\section{Resultados e discussão}

O preparo do arroz (Oryza sativa, L.) e do feijão (Phaseolus vulgaris, L.) é feito pelos auxiliares de cozinha com a supervisão dos cozinheiros ou chefe de cozinha. Uma das primeiras lições recebidas por aqueles que aspiram a um plano de carreira nos restaurantes é preparar o arroz e feijão, por serem consideradas preparações simples e "pelo fato de que cozinhar parece ser uma habilidade natural de todos", ${ }^{10}$ estando vinculada a tarefas de fácil reposição operacional.

\section{Modo de preparo do arroz e feijão}

As tabelas 1 e 2 apresentam os resultados das etapas da técnica de preparação do arroz parboilizado e do feijão preto, em que se observam pequenas diferenças no modo de preparo entre os restaurantes (tabelas 1 e 2).

A prática de lavagem inicial do arroz, antes de sua cocção, foi observada em apenas três UANs. Essa prática implica possíveis perdas de componentes nutricionais hidrossolúveis no arroz polido, principalmente de vitaminas do Complexo B e não interfere no índice de absorção de água. ${ }^{11}$ Assim, pressupõe-se que o rendimento da preparação não será alterado e que a maciez do grão se mantém preservada. 
Tabela 1. Tabela de comparação das etapas do modo de preparo do arroz nos restaurantes de cardápios populares. Rio de Janeiro-RJ. 2012.

\begin{tabular}{ccccccc}
\hline UAN & $\begin{array}{c}\text { Lavagem } \\
\text { do Arroz }\end{array}$ & $\begin{array}{c}\text { Temperos } \\
\text { em água fria }\end{array}$ & $\begin{array}{c}\text { Arroz } \\
\text { refogado } \\
\text { no óleo }\end{array}$ & $\begin{array}{c}\text { Arroz } \\
\text { adicionado em } \\
\text { temperatura } \\
\text { ambiente }\end{array}$ & $\begin{array}{c}\text { Arroz } \\
\text { em água } \\
\text { fervida }\end{array}$ & $\begin{array}{c}\text { Adição } \\
\text { extra de } \\
\text { água }\end{array}$ \\
\hline I & sim & $\operatorname{sim}$ & não & $\operatorname{sim}$ & não & não \\
II & $\operatorname{sim}$ & $\operatorname{sim}$ & não & não & sim & sim \\
III & não & $\operatorname{sim}$ & não & não & sim & não \\
IV & $\operatorname{sim}$ & $\operatorname{sim}$ & não & $\operatorname{sim}$ & não & não \\
\hline
\end{tabular}

Tabela 2. Tabela de comparação do modo de preparo do feijão nos restaurantes de cardápios populares, Rio de Janeiro-RJ, 2012

\begin{tabular}{ccc}
\hline UAN & Remolho & Utilização da água de remolho \\
\hline I & $\operatorname{sim}$ & $\operatorname{sim}$ \\
II & $\operatorname{sim}$ & não \\
III & $\operatorname{sim}$ & não \\
IV & não & não \\
\hline
\end{tabular}

Em todos os restaurantes, os temperos cebola e alho crus são adicionados à água fria juntamente com o sal e óleo, antes de se acrescentar o arroz. Em nenhuma das UANs se observou o processo de refogagem do arroz no óleo. Esse é um procedimento que impede a rápida absorção de água pelo grão, obtendo-se um arroz com aspecto "solto", ${ }^{12}$ resultando em melhor aceitação e apresentação da preparação.
A adição do arroz no caldeirão era feito com água em temperatura ambiente ou em água em ebulição. Na UAN 2, eram acrescidos mais 16 litros de água quente após a adição do arroz na água. O utensílio remo era utilizado como referência para o volume de água.

Segundo Ornellas, ${ }^{12}$ a água em fervura. quando adicionada ao arroz, é totalmente 
absorvida pelo mesmo, aumentando seu índice de absorção, portanto alterando seu rendimento se comparado ao arroz que recebe a água de adição em temperatura ambiente.

No processo de preparação do feijão, três das UANs têm a prática de deixar o feijão de remolho de véspera (tempo médio 5h), contudo apenas uma utiliza a água do remolho para a coç̧ão. Na UAN 4, de maior produção de refeições, por apresentar restrição de espaço físico e disponibilidade de equipamentos, os cozinheiros realizavam a primeira cocção com todo o feijão preto cru que seria utilizado para o cardápio do dia com o mínimo de água, tendo como objetivo inicial amaciar o grão. Após atingir a maciez adequada, os grãos cozidos eram armazenados em cubas sem adição de água. Nas etapas posteriores, parte era macerada, adicionavam-se água e grãos inteiros, e concluía-se com acrescimento dos temperos de alho e cebola refogados para o término do cozimento.

A técnica de remolho é importante, pois atua na diminuição de componentes antinutricionais e flatulentos, aumenta a biodisponibilidade de minerais, mantém o amido resistente, que age como fibra solúvel, além de auxiliar na redução do tempo de cozimento, pois interfere na cocção mais homogênea dos grãos. ${ }^{13} \mathrm{~A}$ escolha da técnica de preparo pode minimizar as queixas dos comensais quanto às preparações, principalmente aquelas que no senso comum são atribuíadas à má digestão.

Os temperos (alho e cebola) são refogados previamente em duas UANs, sendo o óleo desprezado em uma delas e adicionado o sal. Somente na UAN 1 o feijão era espessado liquidificando-se parte do grão e retornando a massa ao caldeirão.

A técnica de preparo não precisa ser única em todos os restaurantes, mas é necessário um planejamento da mesma, adequando-a ao espaço e recursos físicos, preferências da clientela e número de refeições ofertado pela UAN, bem como a legislações sanitárias. No entanto, a UAN, ao padronizar a técnica de preparo, garante a manutenção das qualidades sanitária, sensorial e nutricional, que podem ser reproduzidas por funcionários de diferentes turnos, impossibilitando, assim, a "variabilidade no processo produtivo e, consequentemente, perdas em qualidade e em produtividade". ${ }^{14,15}$

\section{Teste de Aceitação Sensorial}

Na figura 1, são apresentados os percentuais de aceitação das preparações arroz e feijão, por atributo sensorial, entre os trabalhadores dos restaurantes estudados. 


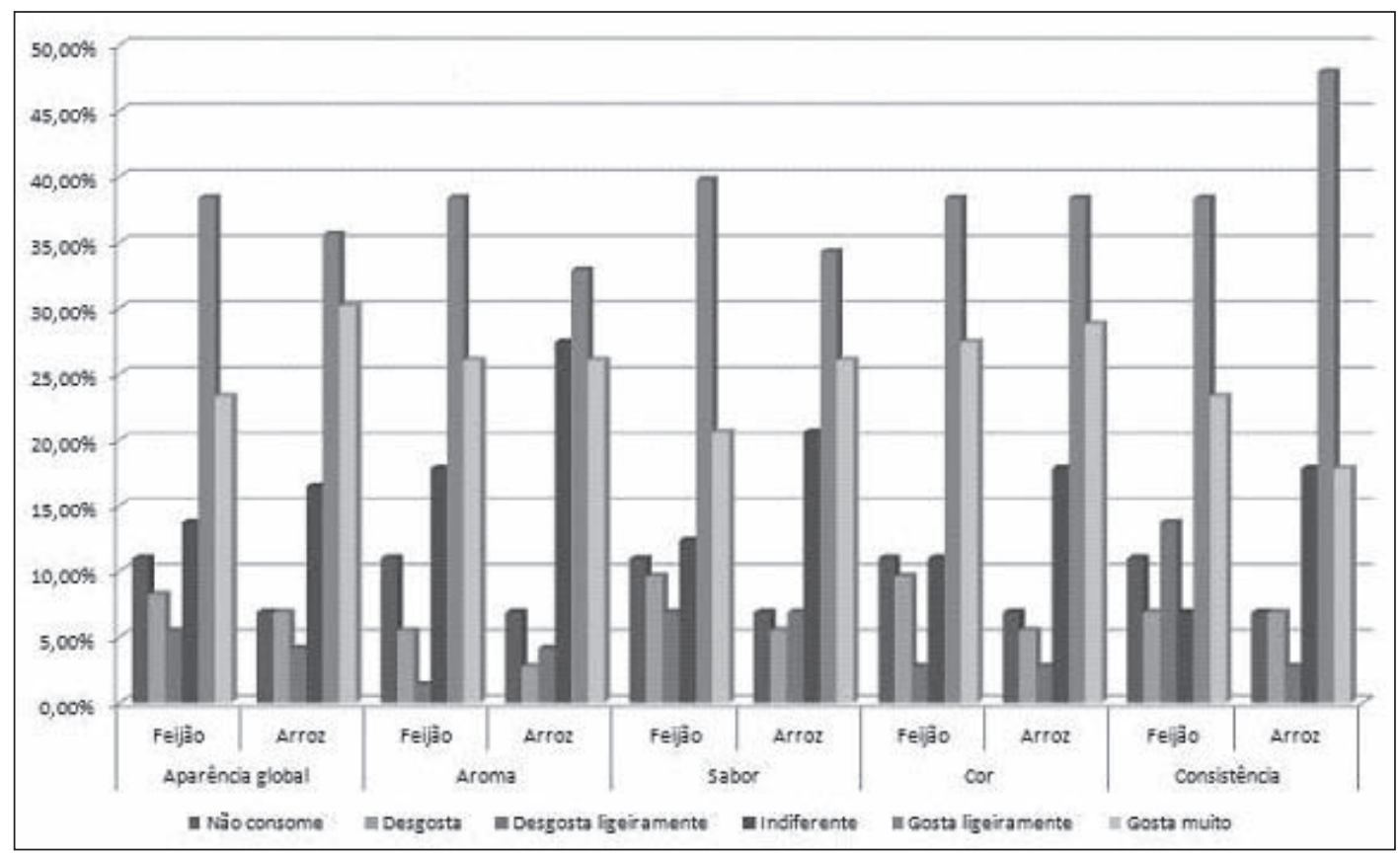

Figura 1. Aceitação Sensorial das preparações arroz e feijão entre trabalhadores de restaurantes de cardápios populares. Rio de Janeiro,RJ, 2011.

Os atributos sensoriais - aroma, sabor, aparência global, cor e consistência - avaliados na preparação arroz, apresentaram, dentre as opções de resposta, a maior aceitação para "gostar ligeiramente" (32,8\% a 47,9\%) dos entrevistados. Entretanto, no atributo consistência, 17,8\% relataram "gostar muito", bem como "indiferente".

O teste de aceitação sensorial da preparação feijão apresentou o mesmo padrão das análises da preparação arroz, em que a opção "gostar ligeiramente" também foi a que apresentou o maior percentual de respostas - 38,3\% para aroma, aparência global, cor e consistência a $39,7 \%$ para sabor.

Muito embora no teste de aceitação sensorial a maioria dos funcionários tenha relatado gostar das preparações, $6,8 \%$ e 10,9\% não consomem arroz e feijão, respectivamente. Os quatro atributos - aparência global, aroma, 
sabor e cor - obtiveram a opção de resposta "desgosta" maior para o feijão $(8,2 \%, 5,5 \%$, $9,6 \%, 9,6 \%$ ), quando comparados às avaliações da preparação arroz $(6,8 \%, 2,7 \%, 5,5 \%, 5,5 \%$, respectivamente).

No caso do feijão, os trabalhadores ressaltaram que não existe um padrão de qualidade da preparação, por isso apresenta consistência e sabor variados ao longo da refeição, devido a ausência ou excesso de temperos e/ou a diluição da preparação a ser servida nos horários próximos ao término do almoço, o que pode desestimular o consumo das preparações.

Outro ponto relevante, apesar de não se ter avaliado no estudo, é que a aceitabilidade do feijão pode ainda ser influenciada pelo modo de armazenamento dos grãos a espera de sua comercialização ou no estoque do restaurante. Alguns estudos ${ }^{16,17}$ demonstram que o armazenamento incorreto desses alimentos pode ocasionar dificuldade de cozimento ou efeito hard-to-cook. Esse efeito é responsável pelo aumento de cozimento desses grãos, o que, nutricionalmente, pode levar a perda de nutrientes e mudanças de conformação de alguns componentes. Fatores como temperatura e umidade também estão relacionados ao aparecimento desse efeito.
O ambiente também é capaz de influenciar a aceitabilidade do feijão. Segundo Bertoldo et al., ${ }^{18}$ este pode realizar uma espécie de seleção natural dos grãos que apresentam características agronômicas insensíveis a diferentes lugares de cultivo, causando melhora do rendimento do grão e consequentemente, possíveis melhoras nutricionais e sensoriais.

\section{Conclusão}

As preparações arroz e feijão por serem de baixa complexidade e rotineiras dentre os processos produtivos da UAN, tendendo a se tornar uma ação mecanizada desprovida de sabor e elaboração e que não considerem a força cultural que ambas as preparações representam para a população.

A revisão e padronização das técnicas dietéticas dessas preparações podem evitar as avaliações insatisfatórias e colaborar para maior aceitação e consumo de ambas.

A fim de contribuir para o aumento do consumo do arroz e do feijão, é necessário haver, nas UANs, maior atenção e aprimoramento das técnicas de preparo, aproximando-se de produções caseiras que são vistas como gostosas e de qualidade por parte de quem as consome, aumentando assim sua procura. 


\section{Referências}

1. Garcia RWD. Reflexos da globalização na cultura alimentar: considerações sobre as mudanças na alimentação urbana. Rev. Nutr. [periódicos na Internet] 2003 [Acesso em 2 maio 2012]; 16(4): 483-92. Disponível em http://www.scielo.br/scielo.php?script=sci_ arttext\&pid $=$ S1415-52732003000400011\&ln $\mathrm{g}=$ en\&nrm=iso

2. Toral N, Slater B. Abordagem do modelo transteórico no comportamento alimentar. Cien. Saude Colet. [periódicos na Internet] 2007 [Acesso em 2 maio 2012]; 12(6): 164150. Disponível em: http://www.scielosp.org/ scielo.php?script $=$ sci_arttext\&pid $=\mathrm{S} 1413$ $81232007000600025 \& \operatorname{lng}=$ pt\&nrm $=$ iso

3. Garcia RWD. Aspectos psicossociais dos hábitos alimentares da população brasileira. In: Anais do 1. Workshop Instituto Danone; 1998 maio 15-16 ; Florianópolis: Instituto Danone; 1998. p.89-99.

4. IBGE. Pesquisa de orçamentos familiares 2008-2009. Rio de Janeiro: IBGE; 2010. p. 52.

5. Monteiro CA et al. A new classification of foods based on the extent and purpose of food processing. Cad. Saúde Pública. [periódicos na Internet] 2010 Nov [Acesso em 2 maio 2012]; 11(26): 2039-49. Disponível em http://www.scielo.br/scielo.php?script=sci_ arttext\&pid=S0102-311X2010001100005\&ln $\mathrm{g}=$ en\&nrm $=$ iso

6. Monteiro et al. Increasing consumption of ultra-processed foods and likely impact on human health: evidence from Brazil. Public Health Nutr. 2011; 14: 5-13.
7. Levy RB et al. Distribuição regional e socioeconômica da disponibilidade domiciliar de alimentos no Brasil em 2008-2009. Rev. Saúde Pública. [periódicos na Internet] 2012 Fev [Acesso em 2 maio 2012]; 46(1). Disponível em http://www.scielo.br/ scielo.php?script $=$ sci_arttext\&pid=S003489102012000100002\&lng=pt\&nrm=iso

8. Mangabeira AS, Botelho BAR. Produção de arroz e feijão em cozinha-show para maior consumo e satisfação de clientes usuários de restaurantes de autosserviço. Nutr. pauta. 2010 Nov/Dez; 18(105): 52-56.

9. Faria EV, Yotsuyanagi K. Técnicas de Análise Sensorial. 2. ed. Campinas: ITAL; 2008. 120 p.

10. Kraemer FB, Aguiar OB. Gestão de competências e qualificação profissional no segmento da alimentação coletiva. Rev. Nutr. [periódicos na Internet] 2009 Out [Acesso em 6 jan. 2012]; 22(5): 609-19. Disponível em: http://www.scielo.br/scielo.php?script=sci_ arttext\&pid=S1415-52732009000500002\&ln $\mathrm{g}=$ en\&nrm $=$ iso.

11. Amato GW. Lavar ou não o arroz? Eis a questão. 2006. [Acesso em 6 jan. 2012]. Disponível em: http://200.96.107.174/cexcelencia/artigos/ files/arq0026.pdf

12. Ornelas LH. Cereais. In: Ornelas LH. Técnica Dietética: seleção e preparo de alimentos. 6 ed. São Paulo: Atheneu, 1995. p. 226.

13. Fernandes AC, Proença RPC. Técnica recomendadas para pré-preparo de feijão: remolho e descarte da água. Nutr. pauta. 2011 Nov/Dez; 19: 50-56. 
14. Akutsu RC et al. A ficha técnica de preparação como instrumento de qualidade na produção de refeições. Rev. Nutr. [periódicos na Internet] 2005 Mar/Abr [Acesso em 14 fev. 2012]; 18(2): 277-79. Disponível em: http://www.scielo.br/ scielo.php?script $=$ sci_arttext $\&$ pid $=\mathrm{S} 1415$ $52732005000200012 \& \operatorname{lng}=$ en\&nrm=iso

15. Silveira BM et al. Padronização de receitas e elaboração de fichas técnicas de preparação de sobremesas. Nutr. pauta. 2010 Maio/Jun; 18: $50-54$.

16. Coelho SRM et al. Alterações no tempo de cozimento e textura dos grãos de feijão comum durante o armazenamento. Ciênc. agrotec. [periódicos na Internet] 2009 Mar/ Abr [Acesso em 4 out. 2011]; 33(2): 53944. Disponível em: http://www.scielo.br/ scielo.php?script $=$ sci_arttext\&pid $=\mathrm{S} 1413$ $70542009000200028 \& \operatorname{lng}=$ en\& $\mathrm{nrm}=$ iso
17. Oliveira, VR et al. Qualidade para o cozimento e composição nutricional de genótipos de feijão com e sem armazenamento sob refrigeração. Cienc. Rural. [periódicos na Internet] 2011 Maio [Acesso em 4 out. 2011]; 41(5):746-752. Disponível em: http:// www.scielo.br/scielo.php? script $=$ sci_ arttext\&pid=S0103-84782011000500002\&ln $\mathrm{g}=$ en\&nrm $=$ iso

18. Bertoldo JG et al. Rendimento de grãos em feijão preto: o componente que mais interfere no valor fenotípico é o ambiente. Cienc. Rural. [periódicos na Internet] 2009 Out [Acesso em 4 out. 2011]; 39(7): 1974-182. Disponível em: http://www.scielo.br/scielo.php?script=sci_ arttext\&pid=S0103-84782009000700004\&ln $\mathrm{g}=$ en\&nrm=iso

Recebido: 20/3/2012

Aprovado: 12/6/2012 